\title{
Danças de um Tempo: Pedagogias da ausência em meio à pandemia
}

\author{
Carolina Romano de Andrade \\ Universidade Federal do Rio Grande do Norte - UFRN, Natal/RN, Brasil \\ E-mail: carolromano@hotmail.com \\ Renata Fernandes dos Santos \\ Universidade Federal do Triângulo Mineiro - UFTM, Uberaba/MG, Brasil \\ E-mail: E-mail: renata.danse@gmail.com \\ Luiza Romani Ferreira Banov \\ Universidade de São Paulo - USP, São Paulo/SP, Brasil \\ E-mail: lu_rfb9@usp.br
}

Resumo

Este artigo propõe refletir sobre a dança, em seu contexto educacional, a partir da situação provocada pela pandemia de Covid-19. A pergunta que orienta a escrita nasce da problemática do ensino de uma arte da presença de modo remoto: o que foi possível mobilizar dessa experiência a fim de se projetar transformações no ensino da dança? Desta forma, apresenta-se na introdução o contexto do ensino remoto emergencial em relação às práticas de dança. Em seguida são descritos três aspectos relacionados a uma aprendizagem em dança: tempo da escuta, poética da distância e permanência no presente. Na última parte o artigo tece sentidos sobre a dança e suas contribuições neste processo de reformulação artístico-pedagógica que exigiu reinvenções de todas as partes envolvidas: crianças, educadores e famílias.

Palavras-chave

Dança. Arte. Educação. Pandemia. Distância.
Abstract

This paper proposes to reflect about dance, in its educational context, from the situation caused by the Covid-19 pandemic. The question that guides the text comes from the problem of teaching an art of the presence in a remote way: what was it possible to gather from this experience in order to project changes in dance teaching? Thus, the introduction presents the context of remote emergency teaching with reference to dance practice. Following this, three aspects related to dance learning are described: a time for listening, a poetics of distance and a state of being in the present. In the last part, the article draws conclusions on dance and its contributions to this process of artistic pedagogical reformulation, which demanded reinvention from all involved: children, educators and families.

\section{Keywords}

Dance. Art. Education. Pandemic. Distance. 


\section{Introdução}

O ano de 2020 transcorreu de maneira inusitada. O Conselho Nacional de Saúde (CNS) anunciou em 26 de março as orientações de distanciamento social, considerando a Declaração de Emergência em Saúde Pública Internacional feita pela Organização Mundial de Saúde (OMS) em 30 de janeiro em razão da pandemia de Covid-19, doença causada pelo SARS-CoV-2, o novo coronavírus.

Diante desse fato, em pouco tempo parte da população precisou se adaptar a uma nova realidade: trabalhos presenciais tornaram-se remotos, pessoas perderam seus empregos, o distanciamento recomendado afastou familiares e amigos por mais tempo do que o imaginado, entre outras mudanças que afetaram sobremaneira os indivíduos. Em semanas, uma nova ordem se instaurou e a educação também viveu a urgência de ser reformulada. Educadores e equipes gestoras de todo o país se reinventaram, enfrentando crises e as muitas fragilidades de nosso sistema de educação. De acordo com a Unesco (2020), desde o dia 12 de março de 2020, as redes de ensino decretaram o fechamento temporário das escolas. Até janeiro de 2021, data de entrega deste artigo, a maior parte dos estados brasileiros permanecia em ensino remoto ${ }^{1}$, em caráter emergencial.

Com pouca formação ou preparação, professores enfrentaram essa situação transformando suas práticas, reinventando estratégias pedagógicas diante da complexa realidade de um país tão discrepante: frente ao ensino remoto emergencial, algumas famílias puderam reequipar suas casas com novos computadores, dispositivos e pacotes de dados de internet, enquanto grande parte da população brasileira não teve meios para que o ensino remoto se efetivasse. Segundo nota técnica do Instituto de Pesquisa Econômica Aplicada - IPEA (2020) sobre o acesso domiciliar à internet e o en-

1 De acordo com Behar (2020), "o termo 'remoto' significa distante no espaço e se refere a um distanciamento geográfico [...] É emergencial porque do dia para noite o planejamento pedagógico para o ano letivo de 2020 teve que ser engavetado". sino remoto durante a pandemia, seis milhões de brasileiros que se matricularam em 2018 não tinham acesso à rede banda larga ou móvel em casa:

[...] nas etapas da educação básica a esmagadora maioria dos estudantes sem acesso está matriculada em instituições públicas de ensino. [...] mais de $80 \%$ das matrículas estão em estabelecimentos públicos. Há, contudo, proporcionalmente mais estudantes sem acesso à internet estudando em tais estabelecimentos, pois é onde estão matriculados 97,5\% desses estudantes. (IPEA, 2020, p. 9).

Foi nesse cenário que nós, um grupo de artistas da dança/educadoras ${ }^{2}$ atuantes em diversos contextos, abrangendo educação formal e não-formal, da educação infantil à universidade, nos reunimos para entender como as relações pedagógicas em dança foram afetadas e poderiam ser adaptadas a esse momento. O grupo se uniu inicialmente por uma chamada aberta realizada pelo Grupo do Facebook "Dança com Crianças", em março de

2 Esse grupo foi formado pelas seguintes artistas/educadoras: i) Carolina Romano de Andrade- Artista da Dança, doutora em Arte Educação, com Pós-Doutorado em Artes pela IA/UNESP e pelo PPGARC/UFRN. E que atua como professora colaboradora do Mestrado Profissional em Artes, PROFARTES, Unesp/SP. ii) Layla Mulinari-Terapeuta Ocupacional, artista da dança e Eutonista formada pelo Instituto Brasileiro de Eutonia. Idealizadora do projeto "Mover Espaços", que promove eventos de dança e educação somática entre pessoas do universo artístico/ sócio/educativo, iii) Luiza Romani Ferreira Banov - Doutora em Artes Cênicas-Dança ECA/USP. Pré-treinadora em GYROTONIC $₫$ e GYROKINESIS $®$ e idealizadora do Núcleo Dédalos de pesquisa de/em movimento. Coordena o grupo de pesquisa Pé de Dança Pedagogias da Dança e Antroposofia (Faculdade Rudolf Steiner/Universidade Federal do Triângulo Mineiro), iv) Renata Fernandes dos Santos Bacharel- Licenciada em dança pela UNICAMP e mestre em Artes pela UNESP, professora de arte/dança da educação básica pública e coordenadora do grupo/linha de pesquisa Pé de Dança: Pedagogias da Dança e Antroposofia (Faculdade Rudolf Steiner/Universidade Federal do Triângulo Mineiro), v) Renata Costa é artista da dança e educadora, desenvolve uma abordagem de ensino pela via da dança/movimento que nomeia de Movimento Criativo. É licenciada em dança pelo Centro Universitário da Cidade do Rio de Janeiro e pós-graduada em Preparação Corporal nas Artes Cênicas pela Faculdade Angel Vianna. 
2020. A partir disso, encontros semanais ocorreram ao longo de seis meses e tinham como propósito partilhar experiências, inquietações e dificuldades vividas em relação às práticas de dança, ao longo da implementação do ensino remoto emergencial.

Muitas questões nos atravessaram nesse período, entre as quais: Como adaptar a dança para o ensino remoto? Como proporcionar, por meio das telas, a percepção das sensações, do contato físico, da respiração? Como equilibrar a exposição excessiva aos dispositivos eletrônicos? Como adaptar as casas para as práticas de dança? Como promover as relações sociais dançadas, nesse contexto? Como incluir as famílias nas práticas de dança? Como acolher os professores pelo viés da escuta? Além dessas questões, uma outra problemática nos inquietou: as discussões acerca da volta às aulas presenciais, que começaram a ocorrer a partir do anúncio de alguns Estados, com previsão de abertura para o mês de agosto de $2020^{3}$.

Neste ínterim, as discussões e as práticas que as educadoras realizaram transformaram-se no e-book Movimentos de Afetos - por um protocolo dançado e poético de volta às aulas ${ }^{4}$, que apresentou uma discussão sobre as possibilidades de práticas artísticas/ pedagógicas em dança que poderiam contribuir para um retorno sensível na volta às aulas no contexto de pandemia. Diante dessa perspectiva, escrevemos com o intuito de ultrapassar o campo dos procedimentos práticos e sanitários. Abordamos o acolhimento, revelando o lugar essencial da arte neste contexto de retorno, bem como as possibilidades poéticas desse "novo encontro", acreditando que a dança contém saberes que são essenciais para essa retomada. Assim, partilhamos as recriações possíveis de nossas práticas artísticas e pedagógicas em dança

$3 \mathrm{~A}$ primeira rede de ensino brasileira a voltar às aulas presenciais foi a de Manaus, em 10 de agosto de 2020. O estado de São Paulo anunciou, em agosto de 2020, o primeiro plano de retorno para 8 de setembro.

4 BANOV et al., Movimentos de Afetos - por um protocolo dançado e poético de volta às aulas ,[s.n.]. Rio de Janeiro, 2020. no contexto de isolamento social e expusemos nossas inquietações no que tange ao retorno à escola.

Nossa pergunta central na escrita do e-book foi: em que a dança pode contribuir com a reorganização e recriação dos espaços e dos afetos (SPINOZA, 2011) durante e após a pandemia? E isso nos provocou, a propor aos que chegam, depois de meses de confinamento em casa e privados do convívio social, uma volta às aulas que acolhesse as novidades e para tanto envolvesse a arte. Como acolher e receber aqueles que vão chegar a uma nova realidade que ainda não conhecem? A filósofa Hannah Arendt (2016) nos diz que os adultos estariam na responsabilidade de apresentar o mundo conhecido às crianças, bem como as crianças ao mundo, já que o conhecem antes do nascimento dos recém-chegados. Neste contexto pandêmico, um novo contexto se descortina para todos nós, adultos e crianças: ainda não o conhecemos, não sabemos ao certo como será estar nessa nova escola. Precisaremos pensar no acolhimento desses "recém-chegados" considerando que todos somos novos nesse contexto: crianças, estudantes, professores e toda a comunidade escolar.

Diante desse cenário, este artigo parte da elaboração da experiência vivida durante a escrita do e-book e revela algumas inquietações relativas às adaptações dos processos pedagógicos em dança surgidas nesse contexto. Sabemos da experiência limitada oferecida pelas telas, sobretudo no caso da dança com as crianças. No entanto, procuramos visualizar qual é a potência do que vem acontecendo. Nesse sentido, cabe a reflexão de Boto:

[...] o que poderemos mobilizar dessa experiência para projetarmos futuras transformações da escola? Alguns já assinalam a perda de qualidade do ensino ministrado virtualmente, já apontam o risco de se transformar a educação presencial em ensino a distância, demonstrando preocupação quanto à reposição integral das aulas perdidas. Outros procuram visualizar qual é a potência do que vem acontecendo; ou seja, quais lições poderemos tirar desse tempo em que a escola não estava à nossa frente? (BOTO, 2020, p. 3). 
Levando em conta essa introdução, este artigo propõe refletir sobre o ensino de dança em caráter remoto a partir da pergunta inspirada por BOTO (2020): o que pudemos mobilizar dessa experiência a fim de projetarmos transformações no ensino da dança? Dessa forma, nos debruçamos sobre três aspectos relacionados a uma aprendizagem em dança: um tempo da escuta, uma poética da distância e uma permanência no presente. Na última parte tecemos sentidos sobre a presença da dança e suas contribuições neste processo de reformulação artístico-pedagógica que exigiu reinvenções de todas as partes envolvidas: crianças, educadores e famílias.

\section{Ensino da dança em tempos de pandemia:} enfrentamentos possíveis

Propusemos colocar em palavras as provocações da prática que pudessem nos indicar novas proposições para a dança; um reaprender inspirado na infância, considerando que a criança é a dimensão fundamental da vida (ANTÔNIO, 2002). Nos deparamos com três aspectos que denominamos tempo da escuta, poética da distância e permanência no presente, disparadores que nos auxiliaram a discutir e partilhar desafios e descobertas da dança-educação e suas práticas nos tempos da pandemia.

\section{Tempo da Escuta}

«Cognitivamente, não somos mais os mesmos. A convivência que viemos intensificando com as telas que ainda nos rodeiam não produz mudanças genéticas, mas altera nossos hábitos cognitivos" (KATZ, 2015 , p. 2). Nesta realidade reconfigurada, foi nas relações remotas que potencializamos a necessidade de um momento de escuta para que possamos, antes de "resolver" uma situação, olhar para ela e compreender o que ela nos diz sobre nós, sobre o outro, sobre o mundo, sobre o momento presente.

Escutar o que o momento tem a dizer nos parece essencial. Os adultos, cuidadores e educadores carecem de estar despertos para ampliar o ouvir. Podemos incluir este sentido nas proposições de dança com as crianças a fim de traba-
Ihar a escuta de uma forma ampla, que ultrapasse a função fisiológica da audição. A escuta é uma das estratégias exercitadas e lapidadas pela dança, enquanto área de conhecimento, que permite nos (re)conhecermos em nossa relação com o tempo/espaço, com os outros e com nós mesmos.

Os estudos somáticos ${ }^{5}$ nos apontam a importância da lapidação dos sentidos para que possamos nos perceber e nos reconhecer no espaço em que vivemos. Ampliando a observação dos sentidos, é possível transcender para um diálogo sensível de percepções, explorações do estado corporal, sensorial de cada um; diálogo sobre medos, felicidades, inseguranças, sugestões e expectativas para o que virá e o que está registrado em cada pessoa. A escuta também está relacionada a uma percepção de si; assim, entendemos que ela é um caminho necessário ao presente momento.

A escuta do corpo é essencial para iniciar e desenvolver o trabalho. Um convite para que, mesmo conectados pela internet e por dispositivos tecnológicos, possamos trazer a atenção para nós, nossas sensações, espaços articulares, tensões, desejos de movimentos e fluxo. (LASZLO; MILLER, 2020, p. 104).

O cultivo de um tempo da escuta também pode ser observado em inúmeras obras de dança desenvolvidas antes e durante a pandemia. É o caso de CASA MUNDO (2020), websérie criada durante a pandemia por Uxa Xavier com curadoria compartilhada de Renata Fernandes, que colocou artistas e crianças em diálogo a partir da pergunta a estas: como vocês estão vivendo o espaço de brincadeira dentro de casa em tempos de confinamento? As crianças respondiam em forma de vídeo curto, realizando sua brincadeira preferida em tempos de isolamento social. Este vídeo era então partilhado

5 A educação somática consiste em um conjunto de práticas que procuram uma integração entre corpo e mente, integração do indivíduo, por meio de um olhar que soma. As práticas somáticas são usadas no universo da dança pois podem dialogar e ampliar suas capacidades motoras e perceptivas. 
com um artista, que, diante da escuta visual, deveria responder em videodança/videocarta à seguinte pergunta: como a brincadeira desta criança te move em relação à sua infância e à sua dança? Uma proposta de escuta que fez surgir um diálogo entre arte e infância, entre crianças e artistas da dança.

Propomos que, para além da aula de dança, a sensibilização da escuta observada nos exemplos acima possa ser vivida por todo o corpo pedagógico e equipe gestora, acolhendo crianças e suas famílias. Isso é necessário para que se possa manter os vínculos afetivos por meio de um corpo que pertence a cada um de nós, pelo viés da manutenção sensível das relações. Uma das proposições para a escuta pensadas por nós, enquanto coletivo, se relacionou a: (a) brincar com as palavras que poderiam se transformar em gestos, danças e movimentos; (b) criar espaço para expressividades que se relacionam com a dança, atrelando desenhos, pinturas, modelagens, entre outros, aos momentos de dança; (c) promover a escuta do corpo, por meio da percepção das respirações, dos diferentes tônus e possíveis tensões corporais.

\section{Poética da Distância}

Um segundo aspecto vivenciado nas adaptações de ensino remoto foi denominado no e-book como poética da distância. A mediação pela tela e pelas tecnologias gerou um confronto entre a "velha" e a "nova" forma de ir à escola. Uma aula não é somente uma aula. O acesso a uma aula, antes da pandemia, significava também a organização do trajeto como preparação do corpo para chegar à escola. Hoje, acessar uma aula significa acessar um link. Esta realidade mudou a maneira como nos organizamos e nos preparamos para estarmos junto ao outro. A poética da distância nasce em uma tentativa de nos aproximarmos, acoIhendo aspectos poéticos e simbólicos que podem surgir, devido ao distanciamento entre as pessoas.

Como estabelecer um contato pelo olhar, pelo som, pela voz? Como substituir esse contato da pele e do tato por outros tipos de contato? Muitas dúvidas surgem no momento em que o contato físico precisou ser transformado. Uma nova forma de vivermos o tempo e o espaço se instaurou e as aulas de dança nos chamaram para não perder a perspectiva lúdica e afetuosa do estar junto.

Isso não aconteceu só nas aulas; artistas de todo o mundo passaram a reinventar suas ações e criações diante da situação pandêmica. Foi o caso do Núcleo Dédalos, que compôs o trabalho Diálogos à distância (2020), uma série de quatro vídeos-poema criados coletivamente e à distância por quatro artistas durante a pandemia. Esta obra, por sua vez, teve como inspiração a peça Sopro (2013), um encontro entre duas artistas, que investigaram os diálogos possíveis entre corpo, palavra, gesto e voz, e a autonomia da mulher em gerir seu próprio corpo no ato tão singular do nascimento.

A performer Marina Abramovic, em 1988, já utilizava a ideia de distância na obra denominada The Lovers, feita junto a seu até então parceiro de vida e de arte, Ulay. Cada um partiu de um ponto oposto da Muralha da China numa longa caminhada, e ambos se encontraram no meio desse trajeto para se despedirem de seu relacionamento e parceria. A performance se encerrou no encontro entre os dois artistas, no meio do percurso, com um longo abraço, para que cada um seguisse seu próprio caminho dali adiante, sem nunca mais se verem. Vinte e dois anos depois, Abramovic realizou no Museu de Arte Moderna de Nova York (MoMA) uma performance denominada The artist is present (2010). Nessa obra, esteve por três meses sentada silenciosamente várias horas ao dia, e os visitantes do museu podiam se sentar na cadeira vazia logo a sua frente, olhando-a frente a frente pelo tempo que desejassem. Nesta ocasião, Ulay fez uma visita ao museu e ali, em plena performance, aconteceu o reencontro de ambos, desde a despedida performática The Lovers. Uma cena emocionante que nos faz refletir sobre a ausência, a distância e o reencontro.

Nas práticas sugeridas em nosso e-book, apontamos para a importância de pensar uma nova conexão com o espaço físico e com o outro. Pro- 
pusemos, entre outras: utilizar os espaços abertos; observar os movimentos e sons das coisas, da cidade e da natureza; criar danças coletivas em espaços demarcados (linhas, círculos, formas geométricas, zigue-zagues etc.), provocando ações de girar, pular, correr, deslizar pelos trajetos. Essas e outras práticas têm a intenção de focar na necessidade de todos estarem juntos. A distância é algo que todos estamos testemunhando neste momento; nesta experiência simultaneamente individual e coletiva pudemos nos inspirar para abrir possibilidades de encontro em tempos de distanciamento.

\section{Permanência no Presente}

Por fim, a última inspiração que nos guiou na tríade elaborada na proposta de um protocolo poético de volta às aulas foi o estado de presença, o qual consideramos que é, também, valorizar o tempo de encontro com o outro. Nesse sentido, reconhecemos a relevância de contemplar o encontro neste possível retorno ou na manutenção dos vínculos no formato remoto.

A dança pode colaborar para minimizar o distanciamento social, dos corpos em movimento, próximos uns aos outros, emitindo cheiros, pulsações, calor, como forma de diálogo sensível, o que nos convoca a refletir sobre o que seja o estado de presença gerado na dança. Dascal (2005) afirma que esse é um estado de vigília que acontece quando você está com a atenção e a intenção dirigida para o momento que está vivendo e se encontra completo na ação que realiza. Segundo a autora, o estado de presença demanda uma condição de atenção e de alerta para sentir, perceber e estar receptivo ao que está ocorrendo em seu corpo e seu entorno. Alcançar este estado se revela desafiador para o aprendizado e para as relações remotas. Isso pode ser visto pelo trabalho do coreógrafo nova-iorquino William Forsythe. No trabalho Dropping curves, e em outros da série Improvisation technologies (1999), ele propõe ações conscientes para a percepção do corpo no espaço. Essa obra inspira o entendimento de que mapear os estados e relações pode ser interessante para fortalecer as conexões da presença no âmbito pedagógico. A situação do ensino remoto deve perdurar e pode se beneficiar da abordagem de uma permanência no presente. A internet é um dos meios de comunicação possível neste momento, e os artistas e educadores podem beber dessas transformações para recriar e proporcionar encontros e criação artística.

Ao mesmo tempo, compreendemos a internet como um ambiente majoritariamente de conteúdos adultos e de fácil acesso para crianças e jovens, que podem se perder em assuntos inadequados para sua faixa etária. Por este motivo, devemos encarar a inserção de crianças e jovens na tecnologia com cuidado e sensatez. Ademais, os estudos de Glöckler (2020) revelam que o excesso de tela não substitui a relação com a presença física.

Em contrapartida, Laszlo e Miller (2020) consideram que em relação ao professor é possível estar presente por meio de uma aula síncrona, mas muito se perde do estado de presença pela internet. Cabe ao educador e aos adultos estarem atentos a essa realidade: a presença física é o primeiro caminho de encontro com o outro. Porém, diante da situação adversa podemos entender as conexões pela internet como um caminho possível para que a dança aconteça.

As práticas remotas de dança nos revelaram que podemos desfrutar, ainda que em menor escala, daquilo que a presença física pode proporcionar no que se refere à exploração de movimentos - e isso deve ser feito de forma muito respeitosa, pelo viés do tempo da escuta, amplificando-se pelo caminho de uma poética da distância no desejo de nos reencontrarmos em um corpo presente por meio da permanência no presente.

\section{(IN)CONCLUSÃO: Gestos inacabados...}

Experimentamos o fim de 2020 e desse artigo como um gesto inacabado, em contínuo tempo de escuta. Como artistas da dança, concordamos com o olhar de Salles (1998) sobre o processo criativo e destacamos que ele está relacionado com a concepção de um processo educativo pedagógico. 
Essa relação entre o que se tem e o que se quer reverte-se em contínuos gestos aproximativos - rasuras que buscam completude. [...] O combate do artista com a matéria nessa perseguição que escapa à expressão é uma procura pela exatidão e precisão em um processo de contínuo crescimento. O artista lida com sua obra em estado de permanente inacabamento. [...] $\mathrm{O}$ objeto 'acabado' pertence, portanto, a um processo inacabado. (SALLES, 1998, p. 78).

Durante o ensino remoto, buscamos esperanças e respostas no corpo em movimento, no gesto, na poesia, e mesmo vivendo um processo inacabado buscamos pistas para a pergunta que move o artigo: o que pudemos mobilizar dessa experiência a fim de projetarmos transformações no ensino da dança? Boto nos inspira ao afirmar:

[...] vivemos em tempos de exceção. E estes tempos exigem, em alguma medida, a reinvenção da educação e da escola. É preciso inventividade. É preciso experimentação. É preciso ter a coragem de criar. E para criar, há de se romper com certezas presumidas e verdades pressupostas. (BOTO, 2020, p. 5).

A reinvenção à qual Boto (2020) se refere torna-se urgente com o acontecimento da pandemia. Aprendemos com a dança a transitar entre estados corporais ${ }^{6}$ e esta habilidade nos possibilitou viver a pandemia com um corpo aberto às transformações exigidas pelo momento. A dança também nos ensina que é preciso seguir em movimento e que o ritmo é muitas vezes ditado por quem dança, mas igualmente pode ser ditado pelo coreógrafo, pelo coletivo ou pela música, pela iluminação, pelo movimento do público, enfim, é um diálogo entre dentro e fora; interno e externo.

6 Estado corporal está relacionado às camadas físicas e psíquicas implicadas no fazer cênico. Ele compreende impulsos internos e sua expressão exteriorizada em movimento e ação, relacionados ao ambiente e à vida do sujeito. Os estados atrelam e tecem inúmeras camadas cognitivas, imaginativas e perceptivas do ser humano em cena, em que o corpo e a mente estão integrados na ação como um só (MINOZZI, 2015).
Por outro lado, na improvisação, a qualquer instante tudo pode mudar e, portanto, devemos estar cientes de nosso repertório, disponíveis ao entorno, atentos ao todo, entregues ao outro. Isso nos diz muito sobre disponibilidade, outro saber incorporado pela prática da dança. A capacidade de sustentação foi mais um conhecimento acionado, uma vez que foi preciso sustentar, superar a falta que a presença física fez e faz, ressignificar as telas a nos mediar.

Baitello Junior (2012, p. 105) nos lembra que a falta é também sensação corporal, pois o nosso corpo é o primeiro lugar que registra a falta. As imagens na tela, em conexão síncrona ou assíncrona, estão a nos lembrar do que éramos, quando dançávamos juntos, e do que somos hoje, com uma tela a mediar nossos encontros. Fomos exigidos a criar uma didática de dança que permitisse a permanência no presente, apesar das telas a nos mediar.

O estado de presença provocado em uma aula de dança presencial não é o mesmo que acontece em uma aula em que temos uma tela entre nós. Isto porque nossos cinco sentidos são ativados de outra forma, diferente da qual estávamos acostumados: não podemos tocar, ver, sentir, cheirar da mesma maneira quando estamos juntos fisicamente.

Por outro lado, o ensino remoto ainda nos possibilita: provocar vivências de conscientização corporal; experimentar outras possibilidades de movimentos; criar relação com a percepção do tempo, com o uso do espaço e com outros elementos da dança, como a composição coreográfica; e, mais ainda, partilhar e apreciar coletivamente o arcabouço de repertórios de dança dos participantes e os disponíveis na internet. A permanência dos estudantes nas aulas remotas de dança atesta que uma nova forma de presença está nascendo em videoaulas, audioaulas e aulas síncronas por plataformas de comunicação digital.

A pandemia trouxe novos desafios, exigindo, dentre outras coisas, uma adequação didática aos meios digitais para repensarmos a importância da dança na educação. Um convite não apenas a professores de dança ou de artes, mas aos pedagogos e equipes gestoras de todo o país, para que 
reavaliem a hierarquização do currículo escolar, em que arte e movimento são muitas vezes preteridos em relação aos demais componentes curriculares.

Foi e ainda será um tempo de se criar uma pedagogia que abra espaço para as poéticas da distância. Mantenha o distanciamento: essa norma sanitária bem poderia ser uma regra coreográfica de uma performance artística. E por que não pensar que de fato seja? Diante do contexto, observamos que a coreografia foi colocada à disposição da sociedade. No mundo pós-pandemia, a escola pós-pandemia será sem dúvida um ambiente mais coreografado, com gestos e protocolos que podem chegar a ser poéticos se algum orientador assim desejar.

Ressaltamos por fim, neste momento único da história, o papel da família como lugar possível da experiência do toque. O toque ativa a pele enquanto órgão sensorial, e isso é essencial para o desenvolvimento cognitivo, motor e sensorial humano. Esse trabalho ocorre organicamente em uma aula de dança ou em ambientes formativos. O toque informa, corrige e orienta a movimentação em quem está aprendendo. Além disso, no ambiente escolar, naturalmente as crianças se tocam em meio às brincadeiras. O toque era muito presente na vida das crianças antes da pandemia. Mesmo com o retorno às aulas, sabemos que atividades de toque pedagógico e intencional não poderão ser promovidas. Abraços, beijos, carinhos, cafunés, trocados diariamente entre as crianças e educadores, também não serão permitidos por muitos meses ainda. Evidencia-se deste modo o potencial existente em cada núcleo familiar para sanar esta demanda.

O fortalecimento do ambiente familiar neste sentido tem a contribuir com o retorno ao ensino presencial. A partir do entrelaçamento do papel pedagógico de famílias e educadores, abriu-se uma oportunidade para que as famílias pudessem atuar na vida de seus filhos de forma mais integrada, unificando o elo entre comunidade, espaço público e educação. Lembrando algo que nos une: para educar o outro, é importante que nos eduquemos anteriormente. $\mathrm{O}$ ato de ser pai, mãe e tam- bém educador é um ato constante de investigação das próprias limitações, mas também do horizonte que se encontra em si mesmo para que isso se reflita e amplie a existência da criança cuidada.

A dança como caminho pode proporcionar mais do que o aprendizado técnico sobre o mover-se e o compor artisticamente. Ela pode, como linguagem da arte, proporcionar a vivência do universo do sentir, do afetar e do ser afetado pelo outro, pelo mundo. Este caráter torna fundamental que ela esteja presente integrando a vida escolar à vida familiar.

Nossa intenção é que o olhar proposto seja um ponto de partida para acolher e nutrir grupos, indivíduos e realidades por meio das relações entre corpo, dança e movimento, e que estas sejam praticadas pelos orientadores ou responsáveis das crianças interessados na potência dessas relações em tempos de pandemia. Com muitas fronteiras borradas dos papéis previamente estabelecidos entre famílias e educadores, poderemos nos alimentar da dança e de seus saberes para viver o presente e o futuro próximo. Este poderá ser preenchido de coreografias sociais e exigirá de nós a criação de novas respostas. $\mathrm{E}$ a dança poderá figurar, com os seus saberes próprios, entre muitas respostas.

\section{Referências}

ANTONIO, Severino. Educação e transdisciplinaridade: crise e reencantamento da aprendizagem. Rio de Janeiro: Lucerna, 2002.

ARENDT, Hannah. A crise na educação. In.: ARENDT, Hannah.(Org.). Entre o passado e o futuro. Tradução: Mauro W. Barbosa de Almeida. 8.ed. São Paulo: Perspectiva, 2016.

ARTIST IS PRESENT, The. Marina Abramovic. Performance. Nova lorque: MoMA, 2010.

BAITELLO JUNIOR, Norval. O pensamento sentado: Sobre glúteos, cadeiras e imagens, p. 149. São Leopoldo (RS): UNISINOS, 2012. 
BANOV et al, Movimentos de Afetos - por um protocolo dançado e poético de volta às aulas ,[s.n.] Rio de Janeiro, 2020

BEHAR, Patrícia Alejandra. O Ensino Remoto Emergencial e a Educação a Distância. Jornal da Universidade, UFRGS, Porto Alegre, 6 jul. 2020. Disponível em: www.ufrgs.br/coronavirus/base/artigo-o-ensino-remoto-emergencial-e-a-educa cao-a-distancia/. Acesso em: 30 dez. 2020.

BOTO, Carlota. Entrevista. In: HONORATO, Tony; NERY, Ana Clara Bortoleto. (Orgs.). História da Educação e Covid-19. Acta Scientiarum. Education, v. 42, n. 1, pp. 3-5, 2020. Disponível em: http://periodicos.uem.br/ojs/index.php/ActaSciEduc/article/ view/54998/751375150637. Acesso em: $30 \mathrm{dez}$. 2020.

CASA MUNDO. Idealização: Uxa Xavier. Curadoria: Uxa Xavier; Renata Fernandes. Produção: MoviCena Produções; Portal MUD. [S.I., s.n.], 2020. Websérie em 9 episódios. Canal Lagartixa na Janela. Disponível em: https://www.facebook.com/ lagartixanajanela/videos/casa-mundo-apresenta\%C3\%A7\%C3\%A3o/565616454123420. Acesso em: $30 \mathrm{dez}$. 2020.

DASCAL, Miriam. Eutonia - O saber do corpo. 2005. 78f. Dissertação (Mestrado em Artes) - Instituto de Artes, Universidade Estadual de Campinas, Campinas,

2005.

DIÁLOGOS À DISTÂNCIA. Criação: Núcleo Dédalos. Piracicaba (SP): 2020. Série de 4 vídeos-poema. Disponível em: https://nucleodedalos.art.br/\#mostra. Acesso em: 30 dez. 2020.
DROPPING, Curves. William Forsythe. In: IMPROVISATION Technologies: a tool for the analytical dance eye. Categoria: Lines. Subcategoria: 2. Complex Operations. [S.I., s.n.]: 1999. CD-ROM (mídia original). Alguns vídeos estão disponíveis no canal GrandpaSafari: https://www.youtube.com/user/GrandpaSafari. Acesso em: 30 dez. 2020.

GLÖCKLER, Michaela et al. Crescer saudavelmente no mundo das mídias digitais: Um guia de orientação para pais, professores e todos os demais responsáveis por crianças e jovens. São Paulo: Ad Verbum, 2020.

IPEA, Instituto de Pesquisa Econômica Aplicada. Diretoria de Estudos e Políticas Sociais. Acesso domiciliar à internet e ensino remoto durante a pandemia. Nota técnica n. 88, ago. 2020. Brasília: IPEA/Disoc, 2020. Disponível em: https://www.ipea.gov.br/portal/ index.php?option=com_content $\&$ view=article\&id= 36561. Acesso em: 30 dez. 2020.

KATZ, Helena. Conexões entre o corpo apps e o mundo regido por editais. In.: Anais do V Encontro Nacional de Pesquisadores em Dança - ANDA 2015. Disponível em: https://www.helenakatz.pro.br/midia/ helenakatz21557582623.pdf. Acesso em: 09 de janeiro de 2021.

LASZLO, Cora; MILLER, Jussara. Corpos em conexão, corpos em presença. Manzuá: Revista de pesquisa em Artes Cênicas, vol. 3, n. 2, pp. 95-116, nov. 2020. Disponível em: https://periodicos.ufrn.br/ manzua/article/view/23207/13465. Acesso em: 30 dez. 2020.

LOVERS: The Great Wall Walk, The. Marina Abramovic; Ulay. China: 1988. Performance. Versão fílmica (65 min.) disponível em: https://publicdelivery. org/ marina-abramovic-the-lovers-the-great-wallwalk. Acesso em: 30 dez. 2020. 
MINOZZI, Carolina. Estados corporais: catalisadores de experiência na criação em dança. 2015. 168f. Dissertação (Mestrado em Artes da Cena) - Instituto de Artes, Universidade Estadual de Campinas, Campinas, SP, 2015.

\section{ORGANIZAÇÃO MUNDIAL DE SAÚDE. Declaração} de Emergência em Saúde Pública Internacional. Genebra: OMS, 30 jan. 2020. Disponível (em inglês) em: https://www.who.int/director-general/speeches/ detail/who-director-general-s-statement-on-ihr-emergency-committee-on-novel-coronavirus-(2019-ncov). Acesso em: 30 dez. 2020.

SALLES, Cecília Almeida. Gesto inacabado: processo de criação artística. São Paulo: Fapesp; Annablume, 168p, 1998.

SOPRO. Criação: Luiza Banov; Marina Henrique (Núcleo Dédalos). Peça de teatro/dança. Piracicaba (SP): 2013.

SPINOZA, Baruch. de. Ética. Tradução Tomaz Tadeu. 2a ed. Belo Horizonte: Autêntica, p. 238, 2011.

UNESCO. Organização das Nações Unidas para a Educação, a Ciência e a Cultura Situação da educação no Brasil (por região/estado). Disponível em: https://pt.unesco.org/fieldoffice/brasilia/covid-19-education-Brasil. Acesso em: 30 dez. 2020.
Recebido: 09/01/2021

Aceito: 04/05/2021 Aprovado para publicação: 29/05/2021
Este é um artigo de acesso aberto distribuído sob os termos de uma Licença Creative Commons Atribuição 4.0 Internacional. Disponível em: http://creativecommons.org/licenses/by/4.0.

This is an open-access article distributed under the terms of the Creative Commons Attribution License 4.0 International. Available at: http://creativecommons.org/licenses/by/4.0.

Ce texte en libre accès est placé sous licence Creative Commons Attribution 4.0 International. Disponible sur: http://creativecommons.org/licenses/by/4.0. 